\title{
Experience with Small Turbomachinery in a 400 Watt Refrigerator
}

\author{
J.D. Fuerst \\ Fermi National Accelerator Laboratory \\ P.O. Box 500, Batavia, Illinois 60510
}

September 1996

Presented at the Cryogenic Engineering Conference and International Cryogenic Materials Conference (CEC/1CMC 95), Columbus, Ohio, July 17-21, 1995. 


\section{Disclaimer}

This report was prepared as an account of work sponsored by an agency of the United States Government. Neither the United States Government nor any agency thereof, nor any of their employees, makes anv. warranty, express or implied, or assumes any legal liability or responsibility for the accuracy, completeness or usefulness of any information. apparatus, product or process disclosed. or represents that its use would not infringe privately owned rights. Reference herein to any specific commercial product, process or senice by trade name, trademark, manufacturer or othenwise, does not necessarily constitute or imply its endorsement, recommendation or favoring by the United States Government or any agency thereof. The views and opinions of authors expressed herein do not necessarily state or reflect those of the United States Government or any agency thereof.

\section{Distribution}

Approved for public release: further dissemination unlimited. 


\title{
EXPERIENCE WITH SMALL TURBOMACHINERY IN A 400 WATT REFRIGERATOR
}

\author{
J. D. Fuerst \\ Fermi National Accelerator Laboratory ${ }^{*}$ \\ Batavia, Illinois 60510 USA
}

\begin{abstract}
A refrigerator similar to one of the Fermilab Tevatron sattellites was re-configured to use turbomachinery instead of the reciprocating equipment typical of the installations. A Sulzer dry turboexpander, Creare wet turboexpander, and IHI contrifugal cold compressor have been installed and operated for about 8000 hours. Experience was gained both with the rotating machincry and with the refrigerator itsclf as it interfaced with the load. Equipment was set up to regulate in the same manner as the reciprocating devices had. Heat loads and operating mode were adjusted and evaluations made regarding the behavior of the devices.

Individual equipment performance is described, as well as system behavior and overall integration of the machinery. In particular, attention is paid to the Creare wet turboexpander. This device is operated for the first time as part of a full scale refrigeration system, testing not only its performance at the design point but also its off design characteristics and behavior in transient situations.
\end{abstract}

\section{INTRODUCTION}

Fermilab's Accelerator Division/Cryogenics Department is responsible for the maintenance and operation of both the Central Helium Liquefier (CHL) and the system of 24 satellite refrigerators which provide $4.5 \mathrm{~K}$ refrigeration to the magnets of the Tevatron synchrotron. ${ }^{1}$ The satellite refrigeration group also operatcs several additional helium refrigerators which are generally tied to the Tevatron sustem but may not be directly involved with operation of the accelerator. One of these systems is located at the antiproton source. This refrigerator (known as PR) is essentially identical to the Tevatron satellites and originally supplied LHe to some electronics associated with antiproton production. Advances in electronics eliminated the need for $4.5 \mathrm{~K}$ operation which allowed the Division to make the PR refrigerator available to the Cryogenics Deparment for use as a test bed. In the last few years PR has been used for a variety of test including operator training and various small experiments. Most recently, $P R$ has been fome to several pieces of high speed turbomachinery. This equipment has operated for the past vear providing data both on individual component performance and on system behavior. Figure 1 is a photograph of the PR refrigerator.

The rotating expansion engines used in the Tevatron satellites are reciprocating devices manufactured by Process Systems. Inc. ${ }^{2}$ These expanders achieve mid - $70 \%$ efficiency and

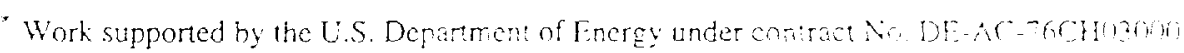




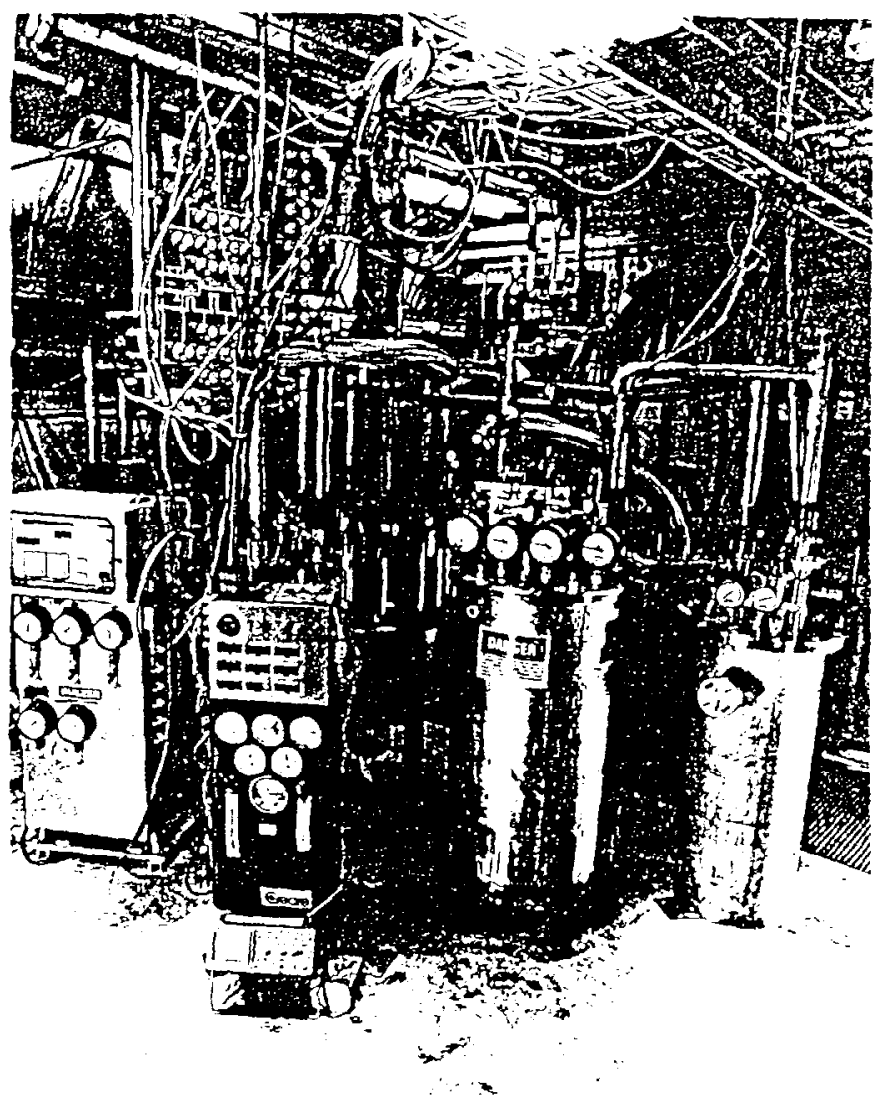

Figure 1: Photo of PR refrigerator huilding bosing (1-r) Sulzer dry expander. Creare wel expander, lont. dewar. ard IHI cold compressor. The value and horizontal heat exchanger are visibie in the hackground.

are well integrated with our existing system. However, they possess drawbacks which make them undesirable in certain other applications. These drawbacks include physical size, maintenance requirements, and flow pulsation created by the positive displacement nature of the units. The Cryogenics Department is interested in gaining experience with high speed rotating machinery, in part to advance the state of the art but also to provide a working system where experiments may be conducted free of flow pulsation. There is considerable experience at the CHL with larger scale turbomachinery; the unique aspect of PR is the use of small devices in a $50 \mathrm{~g} / \mathrm{s}, 400+$ watt refrigerator. This paper describes the system layout, the details of the turbomachinery, and the performance both of individual components and of the overall refrigerator in various operational and upset modes.

\section{SYSTEM DESCRIPTION}

The PR refrigerator was built to supply LHe to three dewars boung clectronics associated with the antiproton source. The plant is based on the Tewan satellite refrigerators, using the same heat exchanger and (originally) reciprocating expanders. Following an electronics upgrade which obviated the need for LHe cooling the refrigerator was idled or used for training or experimentation. In early 1994 the reciprocating cxpanders were replaced with high speed turbomachines which had formerly been in storage. Our prototype centrifugal cold compressor as well as a $160 \mathrm{~L}$ dewar were added to create a complete refrigerator. A $1000 \mathrm{~W}$ heater in the dewar provides the heat load. Figure 2 show's a simplified schematic of the system.

The Tevatron high pressure header supplies about $75 \mathrm{~g} / \mathrm{s}$ of $2 \mathrm{MPa}$, ambient temperature helium to the tube side of the heat exchanger. Part of the supply is precooled in a $\mathrm{LN}_{2} / \mathrm{GHe}$ exchanger before joining the main stream. The gas is then cooled in counterflow with the low pressure $(0.13 \mathrm{MPa})$ return to about $6 \mathrm{~K}$ at the cold end. The dry expander is 


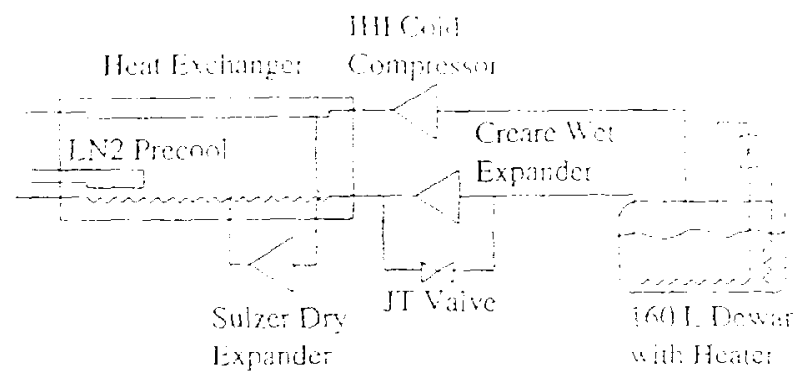

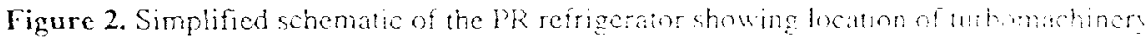

located at the $20 \mathrm{~K}$ point in the exchanger train and takes a (design) flow of $30 \mathrm{~g} / \mathrm{s}$. discharging into the shell side. Tube side pressure drop with these flow rates is about 0.3 $\mathrm{MPa}$, giving a $45 \mathrm{~g} / \mathrm{s}, 6 \mathrm{~K}, 1.7 \mathrm{MPa}$ wet expander inlet. This pressure is less than design for the wet expander and may partially explain the reduced efficiency measured on that unit The wet expander exhausts at pressures at or below $0.3 \mathrm{MPa}$ depending on how the system is configured. Flow passes through a finned tube coil where it is subcooled by the licuid in the 160L dewar before being throttled into the dewar itself. $A$ heater in the dewar maintains liquid level. The cold compressor regulates dewar pressure by drawing vapor from the dewar and discharging to the shell side of the heat exchanger Cold compressor inlet pressure. ranges from $140 \mathrm{kPa}$ (compressor off) to about $50 \mathrm{kPa}$ with the compressor operating at design.

\section{ROTATING EQUIPMENT}

\section{Sulzer Dry Expander}

The standard reciprocating dry $(20 \mathrm{~K})$ expander is replaced with a Sulzer turboexpander consisting of two TGL 16 turbines in series. The units are housed in a common free standing cryostat with all required instrumentation and controls on board, including speed pickups for both shafts. Dynamic (self-acting) gas bearings are used which require no external gas supply. Flow rate is controlled by an electric actuated inlet valve which is controlled via the Fermilab distributed control system. Valves on the turbine brake circuits are used to set shaft speeds. They are manually positioned and require adjustment for optimum efficiency at given inlet conditions. Care must be taken to avoid overspeeding the turbines on startup, either by improper brake valve position or excessive gas flow. The turbines are protected by overtemperature and overspeed interlocks to limit the risk of damage. The brakes are water cooled although we have added supplemental fins and fans to reduce operating temperature.

This expander has been at Fermilab since the mid-1980's and has been installed at various locations within the Division, including (for awhile) a Tevatron satellite refrigera tor. At that time the unit was not configured for remote control of the inlet valve so operations were cumbersome, requiring visits to the refrigerator to adjust flow rate and lurbine speed. In the current installation at PR, the unit automatically regulates flow rate based on discharge temperature. Brake circuits are sill tuned by hand but this has proven acceptable as most brake adjustment occurs during startup and cooldown - once the unit is cold, the turbine speeds are not strongly affected by small changes in inlet valve position as the expander regulates. Table 1 lists dry expander parameters and operating data.

\section{IHI Cold Compressor}

The cold compressor at PR is the same unit described in an earlier paper. ${ }^{3}$ It is manufactured by IHI Co., Ltd. and served as our prototype for units cventually purchased in support of the Tevatron low temperature/higher energy upgrade.t It consists of a single stage impeller and shaft supported by dyanic foil gas bearings and powered by a water cooled variable frequency induction motor. Table 2 shows selected parameters for the compresonr. Performance data is given in the above reference. 
Table 1. Sulzer Dry Turbocxpander

\begin{tabular}{|c|c|c|c|}
\hline \multirow[t]{2}{*}{ Turbine Type: } & \multicolumn{2}{|c|}{$\begin{array}{l}\text { T1: TGL, 16-11/B22 } \\
\text { T2: TGL 16-14/A28 }\end{array}$} & $\begin{array}{l}\text { design speed } 4.7 \mathrm{kHz} \\
\text { design speed } 4.4 \mathrm{kHz}\end{array}$ \\
\hline & $\begin{array}{l}\text { Fuid: } \\
\text { Flow: } \\
\text { Inles: } \\
\text { Ouflet }\end{array}$ & $\begin{array}{l}\text { pure helium } \\
30 \mathrm{~g} / \mathrm{s} \\
1.82 \mathrm{MPa}, 25 \mathrm{~K} \\
\text { ressure: } 0.1221\end{array}$ & \\
\hline Mcasured Perfon & mance: & $\begin{array}{l}\text { Inlet: } \\
\text { Exhaust: } \\
\text { Flow Rate: } \\
\text { Spceds: } \\
\text { Efficiency: }\end{array}$ & $\begin{array}{l}1.58 \mathrm{MPa} .24 .32 \mathrm{~K} \\
0.15 \mathrm{MPa} 14.7 / \mathrm{h} \\
31.6 \mathrm{~g} / \mathrm{s} \\
\mathrm{T} 1.4 .35 \mathrm{kHz} . \mathrm{T} 2: 4.10 \mathrm{kHz} \\
60.8 \% \text { isentropic }\end{array}$ \\
\hline
\end{tabular}

Note: efficiency is measured from upstream of the inlet valve to downstream of turbine 2. Inlet valve $\Delta P$ is $0.16 \mathrm{MPa}$, giving a turbine inlet condition of $1.42 \mathrm{MPa}, 24.24 \mathrm{~K}$ and actual turbine isentropic efficiency of $62.6 \%$

\section{Creare Wet Expander}

Creare Inc. developed a miniature wet turboexpander in the late 1980's which was tested at Fermilab ${ }^{5}$. This research was funded by the U.S. Department of Energy, which took possession of the expander at the conclusion of the project. In turn, Fermilab requested and was granted ownership of the device on behalf of the DOE. Expander performance during the initial tests is reported in the above reference. The unit at that time was essentially a laboratory device which required continuous supervision during operation. This was acceptable for initial operation and proof of concept but further controls and interface work were required to allow "hands free" operation in an industrial setting.

Most important for unattended operation was a means of automating a balancing circuit which maintains equal pressure on either side of the shaft seal. The expander is designed with a labyrinth seal at the lower end of the shaft between the lower journal bearing and the turbine. This seal is exposed to system pressure on one side and is ported to a regulated supply of warm helium on the other side. Since pressure at the system side of the seal varies depending on inlet conditions, the pressure at the other side must be adjusted to maintain zero differential pressure across the seal. Leakage from the process side up into the expander risks freezing out the bearings while leakage in the other direction adds warm gas to the process stream and destroys efficiency. During initial expander testing the labyrinth seal was balanced by observing a differential pressure gauge and manually adjusting a regulator. This action was necessary every few minutes in order to maintain pressure differentials less than $\pm 2.5 \mathrm{kPa}$. Automatic operation of this labyrinth balancing circuit has been accomplished by motorizing the regulator and driving it with a signal from a differential pressure transducer. A Dwyer Capsu-Photohelic gauge with a center zero, \pm $3.7 \mathrm{kPa}$ range, and adjustable limit switches on both the positive and negative side is wired to a Hurst stepper motor attached through a telescoping linkage to the regulator. Control is

Table 2. IHI Cold Compressor

\begin{tabular}{llll} 
& Design & Off Design & Standby \\
& $51 \mathrm{kPa}$ & $41-81 \mathrm{kPa}$ & $142 \mathrm{kPa}$ \\
Inlet Pressure: & sat. vap. & sat. vap. & sat. vap. \\
Inlet Temperature: & $142 \mathrm{kPa}$ & $142 \mathrm{kPa}$ & \\
Ontlet Pressure: & $60 \mathrm{~g} / \mathrm{s}$ & $40-70 \mathrm{~g} / \mathrm{s}$ & $55 \mathrm{~g} / \mathrm{s}$ \\
Flow Rate: & $1.3 \mathrm{kHz}$ & $1.5 \mathrm{kHz} \max$. & $0 \mathrm{~Hz}$ \\
Speed: & $1.25 \mathrm{~kW}$ & $1.5 \mathrm{~kW} \max$ & \\
Input Power: & & & \\
\hline
\end{tabular}


Table 3. Creare Wel Turboexpander

$\begin{array}{lll} & \text { Design } & \text { Measued } \\ \text { Flow Rate: } & 50 \mathrm{~g} / \mathrm{s} & 43 \mathrm{~g} / \mathrm{s} \\ \text { Inlet: } & 1.9 \mathrm{MPa} 6 \mathrm{~K} & 1.8 \mathrm{MPa}, \mathrm{K} \\ \text { Outlet Pressure: } & 0.22 \mathrm{MPa} & 0.25 \mathrm{MP} \\ \text { Pressure Ratio: } & 8.6 & 7.2 \\ \text { Speed: } & 6.4 \mathrm{kHz} & 5.9 \mathrm{kHz} \\ \text { Isentropic Efficiency: } & 72.2 \% & 60 \pm 10 \%\end{array}$

*alculated across expander and inlet valve with valve at igen igen $A \mathrm{P}$ does not include effect of $0.8 \mathrm{~g} / \mathrm{s}$ warm helium fow for hearings, hake. and labyrinth circuit

a simple on/off circuit which drives the stepper motor in the desired direction when the differential pressure across the labyrinth seal exceeds the position of one of the limit switches. Motor step angle is 0.1 degree, with an adjustable frequency of between 5 and $480 \mathrm{~Hz}$. This simple, self contained system has proven sufficiently versatile to provide accurate control of seal differential pressure to within $\pm 1.5 \mathrm{kPa}$ without serious overshoot during normal operation. A more sophisticated control scheme may be implemented in the future which makes use of the Tevatron distributed control system, giving the labyrinth balancing circuit all the capabilities of a standard refrigerator control loop.

Wet expander speed is variable up to $7 \mathrm{kHz}$, with a design speed of $6.5 \mathrm{kHz}$. Shaft speed depends on inlet conditions and the pressure in the brake circuit. The brake consists of a pressurized, water cooled, closed loop helium circuit driven by an impeller attached to the top end of the expander shaft. Brake circuit pressure is controlled with a regulated supply of warm helium to optimize speed for maximum efficiency and to prevent overspeeding when the expander is warm. Shaft speed is sensed with a capacitance probe and displayed on an oscilloscope. Currently the brake pressure is manually adjusted

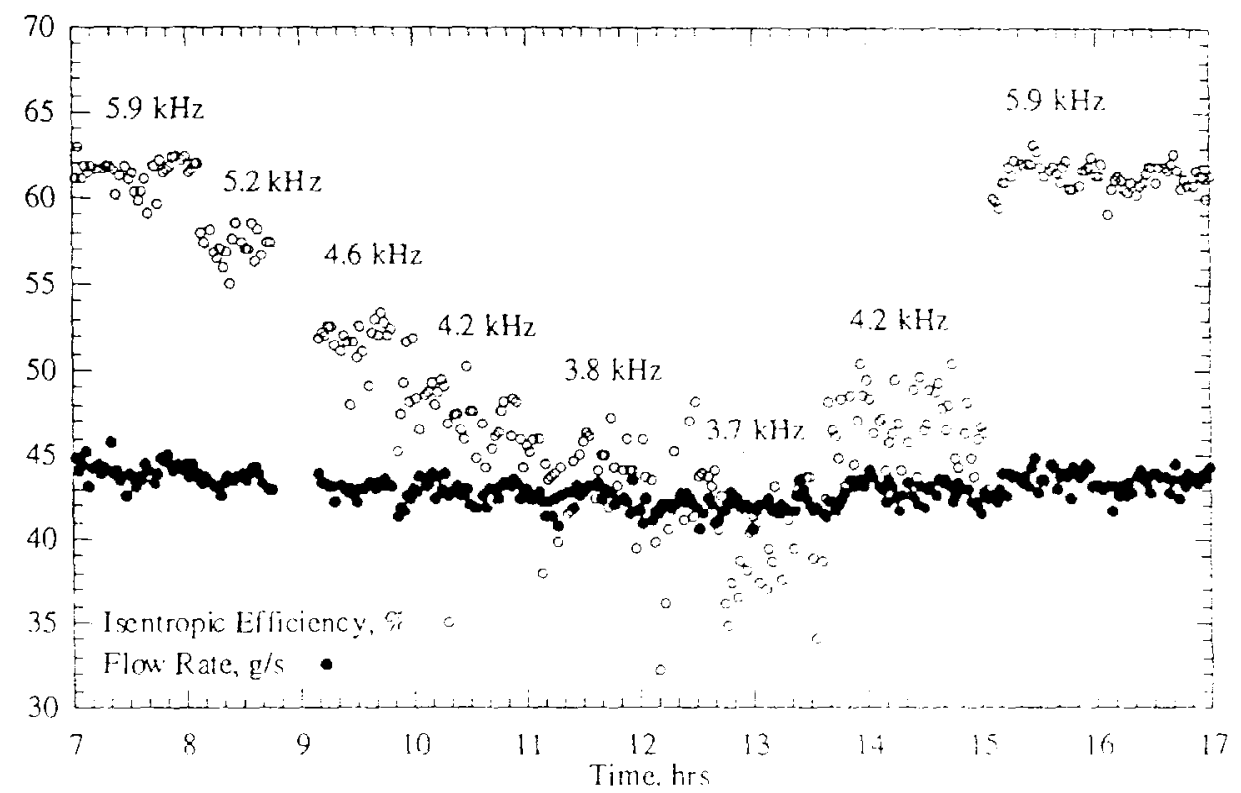

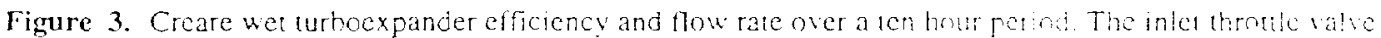
is wide open. Inlet and exhaust pressures are a constant 1.8 and $0.26 \mathrm{MPa}$. hict ienteratute variec fom $5.5 \mathrm{to}$ 6.5K. Frequency numbers correspond to turbine speed as brake pressure is varied hevecen the $0.45 . \mathrm{MPa}$ minimum (producing a maxinum speed of $5.9 \mathrm{kHz}$ - less than the decign of $6.4 \mathrm{kHz}$ and $1.3 \mathrm{MPa}$. the highest safe pressure given the thrust bearing instability. Note mass fow is under the 50 gts design poin'. perhaps due to reduced inlet pressure caused by high pressure drop in the heit chchnger. 


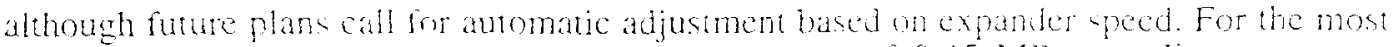
part the brake circuit runs at its minimum pressure of $0.4511 \mathrm{P}$ a so adjustments are infrequent. The cxception is during cooldown when higher brake pressure must be maintained to prevent shaft overspeed. Maximum brake pressure is rated equal to the supply for the expandet's pressurized (static) gas bearings (abour 2 MPa) although we have been limited to $1.3 \mathrm{MPa}$ due to a thrust bearing instability which causes severe, audible shaft vibration at centain ratios of bearing supply to thake supply pressurc. Wet turboexpander parameters and performance are listed in Table 3 and Figure 3.

\section{SYSTEM PERFORMANCE}

\section{Capacities}

Liquefaction and refrigeration capacities were measured directly using the $160 \mathrm{~L}$ dewar and built in $1 \mathrm{~kW}$ heater. Both quantities were measured with and whout the wet turboexpander, substituting an adiabatic throttle valve. Table 4 lists maximum capacities achieved at $P R$ after experimenting with various tunes. Refrigeration at LHe temperature is given directly by heater power required to maintain a stable liquid level while liquefaction rate is measured by the rate of liquid accumulation in the dewar with the heater off. Refrigeration results are in reasonable agreement with Tevatron satellite refrigerator performance in "stand-alone" mode (no LHe injection from the CHL). This is expected since PR is essentially identical to a Tevatron satellite except for the rotating machinery and the load. Liquefier capacity is about $70 \%$ of a satellite in stand-alone mode with wet expander and $40 \%$ of a satellite in stand-alone/JT operation.

\section{Controllability}

A key element of the PR turbomachinery test is to document the behavior of these small units as they interact with the cold box and each other over changes in flow, heat load, and tune. Efforts have been made to provide each unit with regulating capability, al lowing it to adjust tlow rates and speeds as conditions warrant. The $1 \mathrm{HI}$ cold compressor adjusts speed based on its inlet pressure, effectively controlling the temperature of the liquid in the dewar.

Tevatron satellites use the speed of the reciprocating wet expander to control expander cxhaust pressure, thereby fixing the pressure in the "single phase" circuit of the Tevatron magnet strings. The analogy at PR is to allow the Creare wet turboexpander inlet valve to throttle the expander flow based on exhaust pressure. This works quite well from a control standpoint given an appropriate valve/actuator combination. However, overall efficiency of the expander package suffers since some portion of the expansion is performed across a valve with $0 \%$ efficiency. With the inlet valve at $62 \%$ open, the expander inlet pressure is reduced from 1.8 $\mathrm{MPa}$ to $1.3 \mathrm{MPa}$. Although efficiency across the expander itsclf is maintained at $55 \%$, the overall efficiency of the unit (valve plus expanier) is measured to be about $30 \%$.

The Sulzer dry expander operates out of a more loosely coupled control loop than the other two machines. This expander, like the Creare, adjusts flow rate with at throttle valve upstream of the turbines. The control point is the dry expander exhaust cmperature as measured by a hydrogen vapor pressure thermometer (VPT). By careful selection of control loop parameters, this system was made to control to within $\pm 34 \mathrm{kPa}$ on the VPT - a temperature resolution of a few degrees. This is a satisfying recult given the limited useful range of the VPT and the stcepness of the pressure vs. temperature cur e for that device. Of course the Sulzer expander suffers the same efficiency penalty as the Creare imposed by inlet throttle valve positions less than $100 \%$.

Table 4. PR Refrigcrator Capacinic

\begin{tabular}{|c|c|c|}
\hline & We Expander Mode & IT lacesmo \\
\hline Liquefaction & $84 \mathrm{~J} / \mathrm{r}$ & $\because 1 \%$ \\
\hline Refrigeration & $575 W$ & 810 \\
\hline
\end{tabular}




\section{Transients \& Upsets}

There have been ten interruptions in PR operation in the last 16 months, three of which were caused by site-wide power outages at Fermilab. The other stoppages were intentional for equipment maintenance or modification. Each internuption involved a shutdown of all three turbomachines and subsequent restart. This has provided experience with warmup and cooldown of these units. In addition, the safety interlocks were tected during the power outages. In particular, the Creare wet expander is vulnerable in a power outage because it requires a pressurized helium supply for the bearings, brake. and labyrinth balancing circuit. The inlet valve is fitted with a fail closed actuator which shuts off flow to the expander. A bearing gas accumulator provides sufficient ballast to allow the shaft to spin down before the helium bearing supply pressure dwindles (warm gas for bearings, etc. is taken from the Tevatron high pressure header; a power outage shuts down ou compressors causing this header to depressurize.) The Sulzer dry expander and IHI cold compressor use self-acting gas bearings which are pressurized by the process stream and as such are not at risk during an outage.

The wet expander survived the first two power outages with no perceived ill effects. In both cases, the unit was successfully restarted after resumption of power and performance was equal to that before the outage. However, the unit failed to spin up after the third outage which occurred on 22 June 1995. A loud vibration typical of the thrust bearing instability was heard as we re-pressurized the brake circuit in preparation for opening the inlet valve. During this vibration, the speed trace on the oscilloscope went flat, suggesting seizure of the shaft. There has been no shaft motion since. The wet turboexpander operated for about 7500 hours with no maintenance prior to this failure.

\section{CONCLUSIONS}

The PR refrigerator at Fermilab has operated for over a year using high speed turbomachinery instead of the standard reciprocating hardware found in a Tevatron satellite refrigerator. Although efficiencies are less than those measured on reciprocating devices, the units have met the modulation requirements of a satellite. In addition, they are low (or no) maintenance devices which are (or could be) significantly more compact than their reciprocating counterparts. This is important where space constraints, remote location, or accessibility problems outweigh the need for maximum efficiency. Finally, the continuous flow nature of these devices eliminates the flow pulsations and noise inherent in a positive displacement reciprocating machine.

\section{REFERENCES}

1. J.C. Theilacker, Current operating experience and upgrade plans of the Tevatron cryogenic system. in: "Advances in Cryogenic Engineering," Vol. 35b, Plenum Press, New York (1990) p. 917.

2. W.M. Soyars, Operation and maintenance of Fermilab's satellite refrigerator expansion engines, to be presented this conference

3. J.D. Fuerst, Selection of cold compressors for the Fermilab Tevaton. in: "Advances in Cryogenic Engineering:" Vol. 39a. Plenum Press, New York (199.4), p. 863

4. B.L. Norris, Status report of the Tevation lower temperature upgrade. "Crosenics" Vol. 34. Butterworth-Heinemann Oxford UK (1994), p. 73.

5. H. Sixsmith et al, A miniature wet turboexpander, in: "Advances in Cryogenic Fngineering." Vol. 3.5, Plcnum Press, New York (1990), p. 989. 